\title{
Conflito sociambiental nas áreas de lazer em Volta Redonda: a inclusão do slackline no cotidiano da cidade
}

\section{Social-environmental conflict in Volta Redonda leisure areas: the inclusion of slackline in the daily city}

\author{
${ }^{1}$ Marcelo Paraiso Alves marcelo.alves@ifrj.edu.br \\ ${ }^{2}$ Roberto Oliveira Magnago \\ ${ }^{3}$ Ronaldo Figueiró \\ ${ }^{4}$ Milena de Souza Nascimento \\ ${ }^{5}$ Daniela Regina Mulinari
}

\section{RESUMO}

A presente investigação tem como centralidade o conflito socioambiental entre os praticantes de Slackline e o governo municipal de Volta Redonda. Tal conflito se desenvolveu até o final de 2016, principalmente nos logradores públicos do bairro Vila Santa Cecília: ‘Praça Jardim dos Inocentes’ e ‘Praça Brasil'. Diante da configuração singular da proibição na colocação das fitas de Slackline nas referidas praças públicas, emergiu a situação problema desta pesquisa, visto que os praticantes de Slackline foram proibidos de realizar a modalidade esportiva nos espaços públicos do referido município. Diante do exposto cabe perguntar: Como se efetivou o conflito entre o governo municipal e os praticantes de Slackline? Qual a percepção dos praticantes de Slackline sobre a proibição implementada no município? Por fim, quais os impactos destas políticas para a referida prática corporal? Diante desse cenário, o estudo investigou o conflito socioambiental estabelecidos entre o poder público da cidade de Volta Redonda e os praticantes de Slackline. Metodologicamente a pesquisa se aproximou dos Estudos do Cotidiano no intuito de visibilizar as práticas culturais dos sujeitos ordinários que pratica a referida ação corporal. Considerando ser uma investigação que envolveu entrevista com os praticantes de Slackline, ressaltamos que o projeto foi submetido ao Comitê de Ética e aprovado sob o número CAAE: 77005517.0.0000.5237.

Palavras-chave: Conflito Socioambiental. Slackline. Cotidiano.

\section{ABSTRACT}

The present investigation has as centrality the social-environmental conflict between the practitioners of Slackline and the municipal government of Volta Redonda. This conflict developed until the end of 2016, especially in the public contractors of the Vila Santa Cecília district: 'Praça Jardim dos Inocentes' and 'Praça Brasil'. In view of the unique configuration of the ban on the placement of Slackline tapes in these public squares, the problem situation of this research emerged, since Slackline practitioners were prohibited from performing the sporting modality in the public spaces of said municipality. In view of the above, it is necessary to ask: How did the conflict between the municipal government and the Slackline practitioners take place? What is the perception of Slackline practitioners about the prohibition implemented

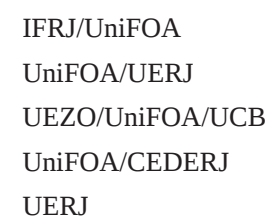


in the municipality? Finally, what are the impacts of these policies on this corporal practice? Given this scenario, the study investigated the socio-environmental conflict established between the public power of the city of Volta Redonda and the practitioners of Slackline. Methodologically, the research approached the Studies of Daily Life in order to visualize the cultural practices of the ordinary subjects who practices the said corporal action. Considering that it was an investigation that involved an interview with the Slackline practitioners, we point out that the project was submitted to the Ethics Committee and approved under the number CAAE: 77005517.0.0000.5237.

Keywords: Conflito Socioambiental. Slackline. Cotidiano.

\section{INTRODUÇÃO}

O presente estudo emerge de uma pesquisa mais ampla junto à Fundação de Amparo a Pesquisa no Estado do Rio de Janeiro que intencionou a produção de inovação no esporte. A investigação parte do pressuposto de que as práticas corporais de aventura, especificamente o Slackline, realizado em áreas de proteção ou áreas caracterizadas como urbanas - parques, jardins, praças públicas localizados em centros metropolitanos, possui a necessidade de estar pautado em planejamentos e articulados a políticas e gestão socioambiental que considere a diversidade de preceitos (BAHIA, 2010; GOMES; DE OLIVEIRA; BAHIA, 2016), no caso deste estudo, no cuidado com árvores nos diferentes espaços da cidade.

Para Pereira et al. (2017) atualmente ocorre um aumento significativo no número de pessoas interessadas em práticas esportivas que fogem das competições cujo os esportes tradicionais são a sua centralidade, seguindo outros estilos de vida e, portanto, outros modos de se tornarem ativos no meio social. Para os autores, esse ethos civilizatório promove o surgimento de outras políticas públicas, em decorrência, a necessidade do reconhecimento dos direitos dos cidadãos, enquanto praticantes de um determinado esporte e, o planejamento de execução de ações que atendam tais demandas.

Considerando que o Slackline possui diversas vertentes - trickline (manobras), highline (altura), o waterline (sobre a água) e por fim o longline (longa distância) (SILVA, POLI E PEREIRA, 2013) -, neste estudo, optamos pela investigação da prática do trickline por ser esta modalidade, dentre as mencionadas, a mais utilizada no cotidiano das cidades, ocasionando, quando não utilizado adequadamente, um conflito socioambiental.

O conflito socioambiental, neste estudo, é entendido a partir das discussões de Acselrad (2004). Para o autor, estes ocorrem quando são envolvidos diferentes grupos sociais e os seus distintos modos apropriação, no caso deste estudo: o governo municipal e os praticantes de Slackline. O autor menciona ainda que um conflito socioambiental se configura quando, pelo menos um dos envolvidos tem a continuidade das formas sociais de apropriação ameaçada.

Especificamente na cidade de Volta Redonda interior do Rio de Janeiro, percebemos o conflito socioambiental instaurado, principalmente até o final de 2016, entre o governo municipal e os praticantes de Slackline, principalmente nos espaços urbanos do bairro denominado Vila Santa Cecília: ‘Praça Jardim dos Inocentes’ e 'Praça Brasil'.

Cabe evidenciar que a colocação do material necessário à referida modalidade provoca um impacto pela tensão entre as árvores: os praticantes de Slackline utilizam "fitas de poliéster com carga de ruptura de cerca de duas toneladas” (PEREIRA E MASCHIÃO, 2012, p. 1).

Diante da configuração singular do Trickline, emergiu a situação problema desta pesquisa, visto que os praticantes de Slackline foram proibidos de realizar a modalidade esportiva nas praças públicas do município 
de Volta Redonda. Diante do exposto cabe perguntar: Como se efetivou o conflito entre o governo municipal e os praticantes de Slackline? Qual a percepção dos praticantes de Slackline sobre a proibição implementada no município? Por fim, quais os impactos destas políticas para a referida prática corporal? Diante desse cenário, o estudo investigou o conflito socioambiental estabelecidos entre o poder público da cidade de Volta Redonda e os praticantes de Slackline.

É importante salientar que, a pesquisa ora apresentado foi desenvolvida em uma perspectiva multicêntrica envolvendo o Centro Universitário de Volta Redonda (UniFOA) e a Universidade Estadual do Rio de Janeiro (UERJ), por meio dos seguintes programas: Mestrado Profissional (Mestrado Profissional em Ensino em Ciências da Saúde e do Meio Ambiente e Mestrado Profissional em Materiais), além dos cursos de Licenciatura em Educação Física e da Faculdade de Tecnologia da UERJ.

Considerando ser uma investigação que envolveu entrevista com os praticantes de Slackline, ressaltamos que o projeto foi submetido ao Comitê de Ética e aprovado sob o número CAAE: 77005517.0.0000.5237.

\section{PRESSUPOSTOS METODOLÓGICOS}

Ao considerar os sujeitos ordinários ${ }^{6}$ em suas redes de relações e a produção de conhecimentos a partir das redes cotidianas (CERTEAU, 1994), trabalhamos com a ideia de que na constituição da cidade, os sujeitos "aprendemproduzem"7 maneiras de "usarfazer" (CERTEAU, 1994) a gestão dos múltiplos espaços de lazer vivenciados na cidade.

É fundamental salientar que ao participar das práticas $^{8}$ socioculturais os praticantes buscaram, nas fissuras, nas brechas deixadas pela ordem dominante, desenvolver aprendizagens alternativas - de gestar a cidade (PARAISO ALVES, 2007) e produzir conhecimentos (OLIVEIRA, 2003) - não determinados pela racionalidade moderna.

Dessa forma, a opção pela noção de redes (OLIVEIRA, 2012) foi necessária por permitir o mergulho no cotidiano, nos processos "reais" fruto do enredamento de práticas, processos históricos, saberes formais e eventos produzidos, buscando compreender os acontecimentos, efetivamente, no chão da cidade, mais especificamente nas ações que emergiram nas atividades de esporte e lazer dos praticantes de Slackline.

Para tal, utilizamos a noção de cotidiano e os modos de usar, bem como as noções de estratégias, táticas, lógicas dos praticantes, com apoio, no trabalho de Michel de Certeau (1994) para mapear as redes de praticantes de Slackline. Para o autor, as práticas cotidianas são produzidas, por meio dos "modos de usar”, como um múltiplo repertório de operações singulares, cujas características principais são: as astúcias, a clandestinidade, a quase invisibilidade.

Nesse sentido, é relevante salientar que tal estudo priorizou as experiências locais (MIGNOLO, 2003; SANTOS, 2005), na intenção de questionar a noção de que os sujeitos que detêm esse tipo de saber, apenas conhecem uma lógica restrita de conhecimento do mundo, e que este conhecimento não tem aplicabilidade para além dele mesmo.

6 O sujeito ordinário aqui concebido emerge da noção de Certeau e Giard (1996), que considera esse sujeito como produtor e não um simples consumidor dos produtos que chega até ele, o homem comum que opera na prática do singular fabricando ações que buscam romper com uma racionalidade que tende a controlar os espaços.

7 A opção pela junção de palavras, busca a referência em Nilda Alves (2001), na tentativa de romper com as limitações que as palavras forjadas a partir do paradigma moderno promovem em nossa percepção e leitura de mundo.

8 Para Certeau (1994), “prático vem ser aquilo que é decisivo para a identidade de um usuário ou de um grupo, na medida em que essa identidade lhe permite assumir o seu lugar na rede das relações inscritas no ambiente” (p. 40) 
Dessa forma, optamos pelos seguintes instrumentos de apreensão de dados: caderno de campo e a roda de conversa. O caderno de campo possibilitou o registro das narrativas dos sujeitos, por meio da anotação detalhada de informações, observações, debates e reflexões que surgiram no decorrer da pesquisa, principalmente quando nos deparávamos com os praticantes no cotidiano da cidade de modo informal.

Já as rodas de conversa eram constituídas com os praticantes que se dispuseram a comparecer no Instituto Federal do Rio de Janeiro campus Volta Redonda (IFRJ-CVR) em horários e dias combinados com os participantes da pesquisa. Ressaltamos que constituímos três encontros com grupos diferentes de participantes, normalmente realizados aos sábados no horário compreendido entre 9h e 12h. As rodas de conversa possuíam um momento de apresentação, onde os participantes mencionavam informações individuais: nome, idade, tempo de prática do slackline e os locais mais utilizados para suas atividades. E um segundo momento em que fazíamos perguntas abertas no intuito de apreender os dados a partir das experiências dos participantes.

\section{CONFLITO SOCIOAMBIENTAL NO COTIDIANO DA CIDADE DO AÇO: PERMANÊNCIAS E RUPTURAS NA PRÁTICA ESPORTIVA.}

Considerarmos que a cidade de Volta Redonda foi gestada na ótica de um Projeto Global, promovendo o estabelecimento e a distinção espacial das habitações, dos espaços e das pessoas - modelo de Company Town (PARAISO ALVES, 2007) -, o que nos permite discutir o modo como esse processo de controle e de hierarquização ainda está presente no cotidiano da cidade estabelecendo o lugar das práticas esportivas no cotidiano e no espaço da cidade.

Inicialmente é fundamental compreender que o pensamento moderno, até então denominado de Colonialidade do Poder e, investido sob a roupagem de uma racionalidade instrumental da ciência e da tecnologia (SANTOS, 2010) opera articulada ao pilar do mercado, provocando inúmeros desastres e degradações ambientais na sociedade atual.

Nesta linha de pensamento, Acselrad (2010) trabalha com a ideia de justiça ambiental, visto que, para o autor, os riscos ambientais são diferenciados e desigualmente distribuídos, dada as diferentes possibilidades dos grupos sociais ao se depararem com as fontes de tais riscos. Para o autor, há uma desigualdade distributiva que necessita ser denunciada, pois o ambiente de certos sujeitos sociais está a prevalecer sobre o de outros, fazendo surgir o que se denomina de Conflito Ambiental. $\mathrm{O}$ autor ainda afirma que tal problema passa a integrar a cultura do direito, pois há a "exposição desproporcional dos socialmente mais desprovidos aos riscos das redes técnico-produtivas da riqueza ou sua despossessão ambiental pela concentração dos benefícios do desenvolvimento em poucas mãos” (ACSELRAD, 2010, p. 109)

Assim, ao considerar que a injustiça social e a degradação ambiental estão articuladas, há a necessidade de se pensar na alteração do modo de distribuição sobre os recursos ambientais, retirando da ordem dominante a capacidade de transferir o débito da conta ambiental à classe social menos favorecida economicamente.

Neste estudo, conforme mencionamos na introdução deste trabalho, estamos pensando o conflito socioambiental, a partir da impossibilidade dos praticantes de Slackline de usarem os espaços urbanos das praças públicas (Jardim dos Inocentes e Praça Brasil) no município de Volta Redonda. Tais espaços estão localizados em uma região que, historicamente, compõe a parte 'nobre' da cidade destinada a uma classe social mais favorecida economicamente: Bairro Vila Santa Cecília.

Sabemos que o referido bairro compõe uma região da cidade que foi planejada pela CSN (Cidade Nova) e incorporou uma classe social diferenciada dos operários que trabalhavam na fábrica, ocupando bairros especí- 
ficos para esta classe social (ALVES, 2001; LOPES 1993). Para Certeau (1994, p. 173) essa seria uma estratégia de “criação de um sujeito universal e anônimo que é a própria cidade”. O autor ainda menciona que:

\begin{abstract}
Nesse lugar organizado por operações especulativas e classificatórias, combinam-se gestão e eliminação. De um lado existem uma diferenciação e uma redistribuição de partes em função da cidade, graças a inversões, deslocamentos, acúmulos, etc. Por outro lado, rejeita-se tudo aquilo que não é tratável e constitui detritos de uma administração funcionalista (na saúde, na seguridade social etc) em meios de densificar as redes da ordem.
\end{abstract}

Ficamos a nos perguntar: Será que a referida espacialidade ainda sofre influência de uma forma de Colonialidade do Poder? Até que ponto há um controle no uso dos espaços da cidade, criando sistemas que estabelecem os lugares próprios aos grupos sociais?

Refletir sobre o modo como a cidade se organiza e, do mesmo modo, é gerida, nos remete novamente a aproximarmos de Acselrad (2010, p. 103), pois:

(...) é por meio desses processos que novos fenômenos vão sendo construídos e expostos à esfera pública, assim como velhos fenômenos são renomeados como "ambientais”, e um esforço de unificação engloba-os sob a chancela da "proteção ao meio ambiente".

Considerando as discussões supramencionadas por Certeau (1994) - controle do espaço urbano - e Acselrad (2010) - conflito socioambiental - gostaríamos de articular duas questões encontradas no cotidiano da cidade: Primeiro, o conflito entre os moradores do bairro, principalmente os que habitam no bairro Vila Santa Cecília - Jardim dos Inocentes e Praça Brasil - e os usuários da praça; Segundo a tentativa de fazer da praça pública (Jardim dos Inocentes) um lugar ordenado e esquadrinhado.

Com relação as duas questões supramencionadas, Certeau (1994) considera que a cidade instaurada pelo discurso urbanístico é definida pela possibilidade de uma tríplice operação: a produção de um lugar próprio; o estabelecimento de um sistema sincrônico; e, conforme já mencionado, a criação do sujeito universal, que é a própria cidade.

No que diz respeito a produção do lugar, Certeau (1994) menciona que o imperativo é a ordem e a lei, estabelecendo distinções e excluindo a possibilidade de duas coisas ocuparem o mesmo local, portanto, implica uma indicação de estabilidade, de controle e de hierarquização, a saber que cada um está no seu devido lugar.

Assim, pensando a partir do autor e, concebendo que, o cotidiano não é uma parcela isolável do social, procuramos em nossas andanças (PAIS, 2003), desvelar na realidade social aquilo que se insinuava nas praças e, simultaneamente, nos remetia ao estabelecimento do referido controle: A imagem do trailer (Figura 1) da Guarda Municipal no Jardim dos Inocentes é emblemática, pois emite uma simbologia de ordem e controle.

Ansioso por saber o impacto e as ações deste dispositivo de poder (FOUCAULT, 1997), em junho de 2016, estivemos na praça Jardim dos Inocentes, na condição de flâuner, aquele que explora o espaço e nele interfere, com sua cultura e sua historicidade (PALOMBINI, 2009), no caso de nosso estudo, a reapropriação do espaço urbano, por intermédio da cultura corporal.

Assim, ao iniciarmos a montagem do equipamento para a prática do Slackline, um guarda municipal nos interpelou salientando que não poderíamos praticar o referido esporte, pois havia uma lei que proibia a coloca- 
ção de amarras nas árvores do município de Volta Redonda (EPISÓDIO DO CADERNO DE CAMPO DO DIA $16 / 06 / 2018)^{9}$.

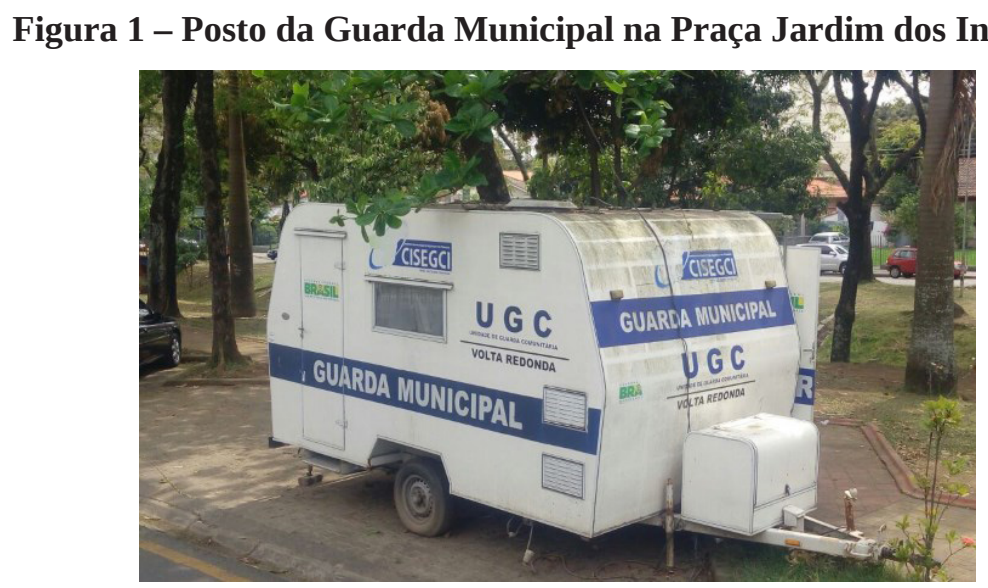

Fonte: Jornal Diário do Vale - 03/03/2015

Os praticantes de Slackline entrevistados narram o modo como a guarda municipal alegou a proibição da colocação dos equipamentos do referido esporte:

O: Já fui proibido várias vezes de andar... mas a galera andava mesmo assim. A alegação era que depredava a árvore, a árvore não tinha sustentabilidade para aquele tipo de atividade. Falavam que estava prejudicando o meio ambiente.

V: Tem um amigo meu que também tinha interesse em praticar Slackline, a gente tinha conseguido emprestado uma fita...mas também no Jardim dos Inocentes ele foi tentar esticar, mas não conseguiu...eu não sei qual foi a alegação da guarda municipal.

Considerando a proibição da Guarda Municipal, quanto ao uso da praça pública (Jardim dos Inocentes), para a prática do Slackline, procuramos informalmente, na semana posterior ao ocorrido (dia 24/06/2018), conversar com uma residente do bairro que mora em frente à referida praça e, descobrimos que a Associação de Moradores havia sido responsável pela retirada dos bancos que haviam na referida praça. Segundo a moradora, a associação solicitou a retirada em decorrência dos inúmeros casais que procuravam a praça para namorar (EPISÓDIO DO CADERNO DE CAMPO DO DIA 24/06/2018).

Nos parece que de certa maneira, os moradores do bairro não admitem outra existência para além daquela que a constituiu: o planejamento, a limpeza, as práticas organizadoras. Para Magri (2006, p. 36) na funcionalidade urbana tudo que advém de práticas produzidas sob outras referências rejeita "as partes indesejáveis que borram a beleza que a expõe como produto. Os pobres são excluídos, rechaçados, empurrados aos guetos suburbanos, aos morros e aos interiores da face maquilada das cidades".

Pensando no conflito estabelecido entre os moradores (os projetistas da cidade) e os sujeitos ordinários da cidade - praticante Slackline -, me recordo de Certeau (1994) e das noções de estratégias e táticas. Para o autor, estratégia se configura como: cálculo ou manipulação das relações de força, um esforço racional que determina um entorno, um lugar para a prática do poder ou vontade (CERTEAU. 1994, p. 99).

9 A opção pelo uso do caderno de campo como instrumento de pesquisa, se deu pela dificuldade de entrevistar a guarda municipal e os moradores do local, visto que não queriam ser identificados. 
Considerando o exposto, percebemos o estabelecimento do sistema sincrônico (CERTEAU, 1994, p. 173), aquele que instaura no cotidiano da cidade a perpetuação de um modo de comportamento que busca universalizar pessoas e cultura, pois estabelece comportamentos e ações: "estabelecer um não-tempo ou um tempo sincrônico, para substituir as resistências inapreensíveis e teimosas das tradições (...)”. As narrativas do praticante de Slackline, revela sinais da organização racional que se perpetua no cotidiano da cidade:

G: Fui proibido por dois guardas municipais, que se identificaram como sargento da guarda. Segundo eles... era proibido pela lei das amarras: não pode estar amarrando nada em postes ou árvores em Volta Redonda. Você vê aí... na época do natal a decoração nas árvores ficam dias e dias. E a gente estava praticando o esporte lá...e eles chegaram alegando isso daí..

Ficamos a pensar na narrativa supra apresentada, em que o praticante de Slackline menciona a contradição na colocação das amarras, pois localiza entre a proibição das práticas irreconhecíveis pela ordem dominante (Slackline), o uso de amarras pelo próprio - Prefeitura Municipal de Volta Redonda -, o poder que instaura e legitima o que pode ou não ser utilizado nas árvores do município. O que é mais perigoso: a colocação do equipamento de Slackline por algumas horas ou a colocação de fios de energia com risco de curto circuito por um período de trinta dias? Outro praticante de Slackline narra o modo como foi proibido de praticar o esporte e revela evidências sobre o uso da cidade:

L: Uma vez no Jardim dos Inocentes estávamos eu, o V. e um amigo nosso... nós tentamos montar... nós estávamos esticando a fita pra começar a catracar... surgiu um guarda daquele trailer que fica no Jardim dos Inocentes, alegando que não poderíamos esticar a fita ali, pois tinha uma série de proibições que não deixavam a gente colocar...eles falaram que a gente tinha que ter uma licença de alguns biólogos da secretaria de meio ambiente...que a prática do Slackline feria as árvores mesmo com todos os equipamentos de proteção que nós mostramos pra ele...mas ele falou que não poderíamos fazer ali, que a gente poderia fazer em um lugar mais afastado em que a guarda não tivesse acesso.

Figura 2 - Imagem das árvores no bairro Vila Santa Cecília em Volta Redonda com amarras ou fios

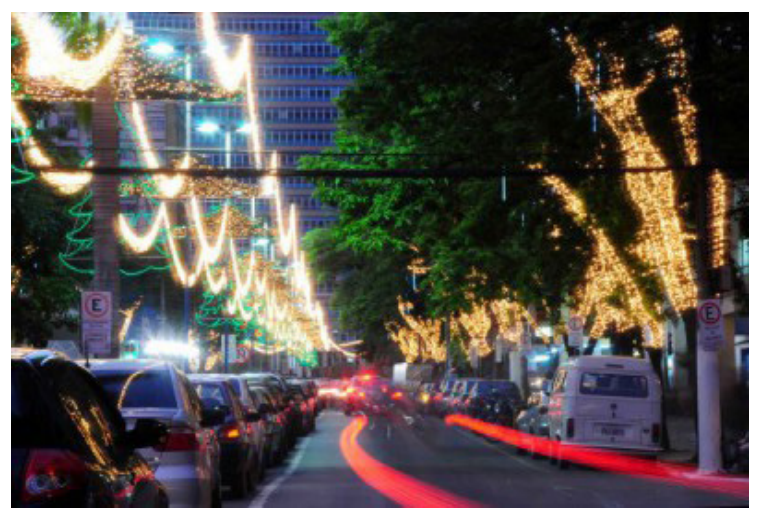

Autoria: Jornal Diário do Vale do dia 11/12/2015

Para Pais (2003, p. 56), ao viajar no cotidiano, o pesquisador "não vê as coisas em si, ou melhor, vê as coisas reduzidas aos seus signos, os quais irrigam e avolumam as representações sociais, as visões de mundo". Dessa forma, o autor considera ser este o caráter enigmático do social: o visível e o invisível, o literal e o secreto. Portanto, nos parece que o modo como o guarda concebe a cidade se revesta enigmáticamente, da lógica construída na gênese de Volta Redonda - Cidade Nova e Cidade Velha - se apresentando a partir da noção de Cidade-conceito, aquela que privilegia a organização funcional e panóptica. 
O que busco salientar é a autorização do guarda municipal para que os praticantes de Slackline montassem o equipamento em outro lugar, mais afastado, em que a guarda não tivesse acesso. Diante do exposto cabe refletir: A guarda municipal não tem acesso a todos os logradouros públicos? Até que ponto essa narrativa nos apresenta indícios de uma política social instaurada no cotidiano da cidade? Considerando que nenhuma outra praça pública, exceto a Praça Brasil, também localizada no bairro Vila Santa Cecília, possui trailer da guarda ou da polícia militar, não seria uma forma de coibir ações que não interessam aos moradores do local? Seria esta uma decisão no intuito de evitar a reinvenção das praças pelos cidadãos de Volta Redonda? Outrossim, me recordo das questões discutidas por Palombini (2009, p. 296) e do questionamento realizado pela autora: "É a cidade que habita os homens ou são aqueles que moram nela?” A autora problematiza a cidade de Paris com o advento da modernidade, explicitando sua polifonia e o caráter múltiplo que a configurou. A burguesia parisiense desconfiava do fenômeno emergente (multidão), visto que o seu espaço privado (residência) foi constituído em oposição ao mundo, na tentativa de proteger a si mesmo e sua família. A autora ainda nos remete a perceber que na sua privacidade, o lar burguês possuía o culto de uma harmonia entre decoração e práticas de sociabilidade civilizada e ordenada, se contrapondo a classe popular:

O mesmo não ocorre com as classes populares, cuja habitação - densamente povoada - leva a uso privativo do espaço público e é apontada como fonte de perturbação da ordem pública, de instabilidade política e de problemas sanitários ao longo do século XIX (PALOMBINI, 2009, p. 296). Grifos do autor.

Ademais, ao pensar na autorização do guarda municipal e, simultaneamente, na discussão de Palombini (2009) sobre a idealização burguesa e o uso da cidade, onde a ocupação do público pela classe popular é tida como uma perturbação, me recordo de Lopes (1993) ao tecer suas reflexões sobre o processo de homogeneização e o modo como os operários da CSN na Cidade do Aço eram orientados ao chegar na cidade:

(...) podia incluir uma passagem inicial pelo hospital para exames de saúde, fichamento numa espécie de balcão de acesso ao emprego, cuidados higiênicos, troca de roupas por uniformes e instruções sobre o uso dos espaços públicos e privados. O uso das habitações obedecia a um trabalho pedagógico explicitamente dirigido às mulheres e impunha padrões funcionais, higiênicos e de comportamento, que se entendiam à esfera dos rituais de celebração e convívio de vizinhança, como festas, diversões e comemorações (LOPES, 1993, p. 105). (Grifos do autor).

Para Certeau (1994, p. 201) o lugar "é a ordem (seja qual for) segundo a qual se distribuem elementos nas relações de coexistência. Aí se acha, portanto, excluída a possibilidade, para duas coisas, de ocuparem o mesmo lugar”. Dessa forma, o autor nos adverte que o lugar se define pela estabilidade e pela ausência de cruzamentos.

Nos parece que no cotidiano da cidade, pelo menos no que diz respeito às praças públicas ora investigadas, são concebidas como uma extensão da residência privadas dos moradores da Vila Santa Cecília. Diante do exposto fico a refletir: Até que ponto a praça não foi concebida como uma extensão do espaço privado dos moradores do bairro Vila Santa Cecília? Será que a retirada dos bancos e, a impossibilidade das pessoas de outras localidades da cidade de permanecerem e desfrutarem do logradouro público perpassa por uma injustiça socioambiental?

Pensando nas questões supramencionadas e na proibição imposta pelo governo municipal aos praticantes de Slackline do município de Volta Redonda, no período compreendido entre 2012 e 2016, este projeto de pesquisa, articulado a uma perspectiva de inovação, propusemos a elaboração de um material que permitisse a retirada do equipamento de Slackline das árvores, superando a possibilidade de impacto socioambiental.

Assim, repensar a cidade sob outra racionalidade requer perceber que a rua e os logradores públicos geometricamente organizados podem ser transformados pelos sujeitos em um lugar praticado. Para Certeau (1994), o lugar praticado seria alterado para a noção de espaço, sendo caracterizado pelo seu avesso, pois toma em conta 
os vetores, a complexidade: “O espaço é o cruzamento de móveis. É de certo modo animado pelo conjunto dos movimentos que aí se desdobram (CERTEAU, 1994, p. 202).

Neste sentido, o bairro Santa Cecília é caracterizado historicamente como sendo o centro de Volta Redonda, devido as suas diversas formas de ocupação e permanência, como por exemplo: lojas, shopping, academias de ginástica, bares noturnos, restaurantes, lanchonetes, Zoológico municipal, cinemas, teatro; passagem dos transportes públicos, pois todas as empresas e quase todas as linhas de ônibus convergem para essa região da cidade. Nessa lógica, a Vila Santa Cecília emerge como um espaço destinado aos encontros e fruição de lazer para os diversos tipos de classe social e faixa etária. A biblioteca municipal e o Memorial Zumbi dos Palmares são reconhecidos na cidade pela referência em eventos políticos, culturais, feiras, exposições, eventos musicais. O principal portão de entrada para a Companhia Siderúrgica Nacional (CSN), que já palco de inúmeras manifestações políticas ao longo da história da ‘Cidade do Aço’.

Nessa linha de pensamento, ao perguntarmos aos praticantes de Slackline sobre o local utilizado para a prática do esporte e o modo como se organizavam as respostas eram unânimes: Primeiro, a facilidade de organização dos grupos para a pratica coletiva do esporte; segundo, a facilidade de transporte para a convergência das praças do bairro Vila Santa Cecília - Praça Brasil e Jardim dos Inocentes, locais proibidos de montagem do equipamento de Slackline.

Pensando no primeiro aspecto, a opção pela prática coletiva, Simmel (2006, p. 60) considera que:

(...) a sociação é a forma (que se realiza de inúmeras maneiras distintas) na qual os indivíduos, em razão de seus interesses - sensoriais, ideais, momentâneos, duradouros, conscientes, inconscientes, movidos pela causalidade ou teleologicamente determinados -, se desenvolvem conjuntamente em direção a uma unidade no seio da qual esses interesses se realizam.

Pensando na ótica estabelecida pelo autor, a sociabilidade assume a partir de distintas formas de feições, uma característica diversa: dramatúrgica, cênica, estética, no caso de nosso estudo poderíamos dizer que em detrimento das práticas corporais de lazer, a ocupação do tempo livre e o caráter lúdico e prazeroso.

Em outro momento, Simmel (2006, pp. 59-60) no intuito de frisar o modo como a sociabilidade se constitui, reitera sua construção a partir de impulsos ou de certas finalidades:

Instintos eróticos, interesses objetivos, impulsos religiosos, objetivos de defesa, ataque, jogo, conquista, ajuda, doutrinação e inúmeros outros fazem com que o ser humano entre, com os outros em uma relação de convívio, de atuação com referência ao outro, com o outro e contra o outros, em um estado de correlação com os outros.

Assim, ele define, como conteúdo e matéria das sociabilidade "tudo o que existe nos indivíduos e de toda a realidade histórica como impulso, interesse, finalidade e tendência (...) (IDEM, p. 60).

Com relação ao segundo aspecto (convergência para a Praça Brasil e Jardim dos Inocentes), nos parece que existem questões significativas que promovem o deslocamento dos praticantes para esta região da cidade: econômica em detrimento do trabalho de múltiplas pessoas; o deslocamento, se considerarmos que os transportes coletivos que partem de diversas regiões da cidade convergem ou passam pelo referido bairro); histórico, pois há uma cultura in-corpo-rada pelo imaginário social, que estabelece esta localidade como o centro da cidade, a disposição do centro econômico que de fato desloca um grande contingente de pessoas para este espaço, em detrimento das atrações culturais e de lazer que possui. 
Diante do exposto, o material elaborado por este estudo objetivou interferir no contexto social do município de Volta Redonda, de modo a contribuir com a retirada dos equipamentos de Slackline das árvores no intuito de minimizar o impacto socioambiental proporcionado pelos praticantes da referida cultura corporal de movimento.

Para finalizar, torna-se relevante salientar que, já existem no mercado modelos similares ao proposto neste projeto, entretanto, a originalidade do equipamento proposto equipamento (PARAISO ALVES; MAGNAGO; MULINARI, 2018) está na constituição deste a partir de polímero, possuindo a especificidade de evitar o uso da madeira em sua constituição, contribuído com o meio ambiente e, por ser impermeável não apresentaria problemas com umidade, conforme os materiais constituídos de madeira, o que o torna um material com maior ciclo de vida (QUINTANA et al., 2018).

Outro aspecto importante no equipamento são as três possibilidades de altura para a montagem do equipamento, visto resguardar os limites de altura respectivos à habilidade e técnica do praticante (Figura 8).

De outro modo, conforme podemos perceber na figura 9 é possível realizar a colocação do equipamento em meio às árvores, minimizando o impacto no meio ambiente, mas permitindo que o praticante reinvente o uso dos espaços e logradores públicos a partir de sua lógica e de seus anseios e interesses pessoais e coletivos.

Figura 8 - Possibilidades de altura para a montagem do equipamento, de forma a resguardar os limites de altura respectivos à habilidade e técnica do praticante
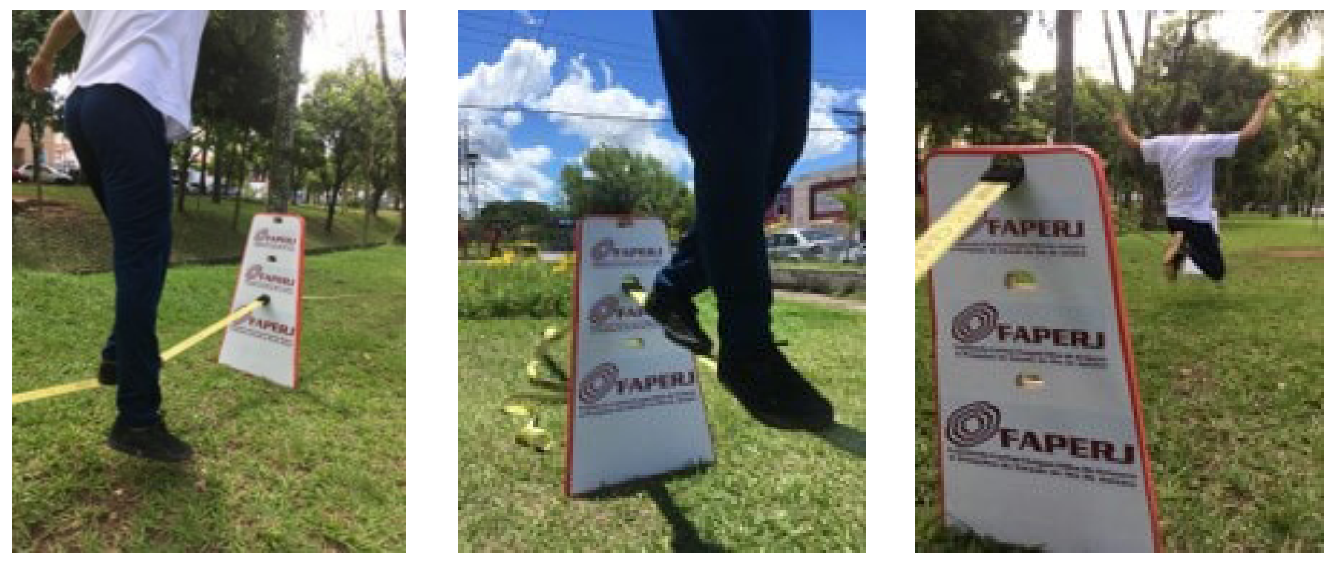

Fonte: Dos autores, 2019

Figura 9 - Possibilidade da colocação do equipamento em meio às árvores, minimizando o impacto no meio ambiente

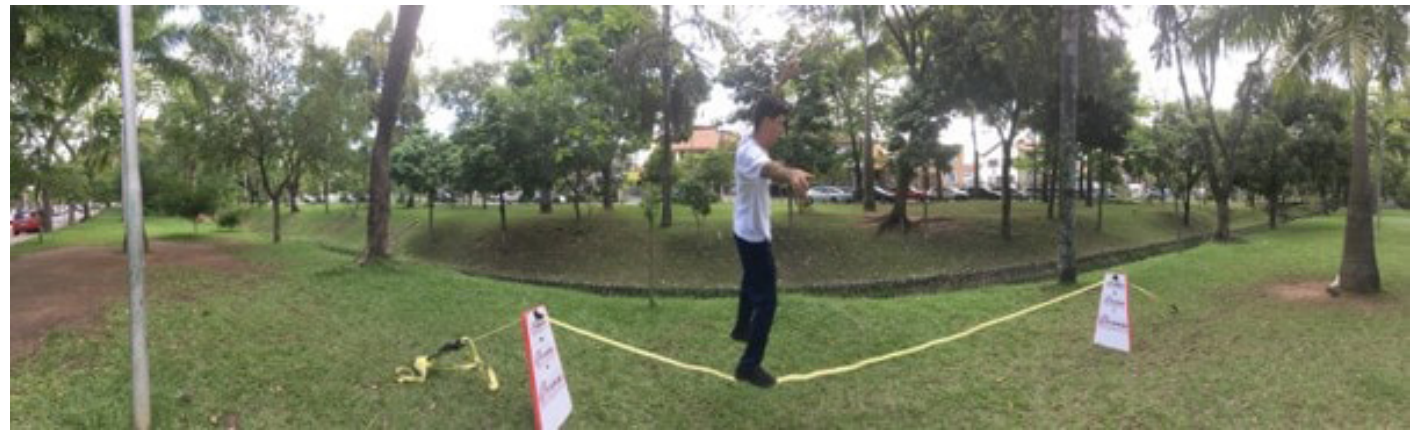

Fonte: Dos autores, 2019. 


\section{CONSIDERAÇÕES}

Com base nos resultados das propriedades térmicas e mecânicas obtidas dos compósitos, consideramos que:

Os tratamentos superficiais realizados nas fibras influenciaram nas propriedades mecânicas e térmicas dos compósitos, mas optar para esse tipo de material visando à criação do protótipo gastaria tempo, energia e mais gastos. Então a melhor opção seria utilizar fibras in natura e agente compatibilizante, ou somente fibras in natura como reforço em PP. A quantidade de fibras inseridas também influenciou nas propriedades, a melhor opção seria utilizar 30\% de reforço, conforme pode-se verificar em Dantas, I. R.; Zanini, N. C.; Cipriano, J. P.; Capri, M. R.; MULINARI, D. R (2018) e Zanini, N. C.; PAIXAO, W. A.; DANTAS, I. R.; MULINARI, D. R. (2018).

Dessa forma, a utilização de fibras da palmeira com reforço em matriz de PP é uma alternativa, resultando em um material de diferentes propriedades dos componentes puros, constituindo uma opção para a redução de custos em aplicações para a criação de cavalete e também ajudando na preservação do meio ambiente.

Para finalizar, foi construído um protótipo de madeira para que pudéssemos fazer a primeira testagem do equipamento em seu tamanho original (ver fig. 11). O material foi testado e aprovado pelos praticantes do esporte.

Cabe considerar que, não conseguiremos finalizar a pesquisa construindo o equipamento esportivo no tamanho original e a especificação do polímero aprovado no estudo, devido a necessidade de uma injetora industrial para a fabricação do molde. Ressaltamos que na região não foi possível encontrar uma empresa que realizasse o referido procedimento (injeção de polímero em moldes com as especificações). As empresas mais próximas da região e que, realizam a injeção estão localizadas em São Paulo e o orçamento, em torno de 70.000,00 (setenta mil reais), valor não inserido no orçamento, o que também inviabilizou a sua fabricação.

\section{REFERÊNCIAS}

ALVES, Marcelo Paraiso. Lazer Operário e Alienação (Volta Redonda 1951 a 1956). Vassouras, 2001.143 f. Dissertação (Mestrado em História) - Coordenadoria de Pós-Graduação, Programa de Mestrado em História, Universidade Severino Sombra, 2001. p.125.

CERTEAU, Michel. A invenção do cotidiano: 1. artes de fazer. 7 ed. Petrópolis, RJ: Vozes,1994. p. 351.

DA SILVA, Eduardo Ângelo; DA SILVA, Leonardo Ângelo. Industrialização, urbanização e formação de classe em Volta Redonda (1945-1979): do fim do Estado Novo aos tempos da Ditadura. Mundos do Trabalho, v. 3, n. 5, p. 86-113, 2011.

Dantas, I. R.; Zanini, N. C.; Cipriano, J. P.; Capri, M. R.; MULINARI, D. R. Influence of Coupling Agent on the Properties of Polypropylene Composites Reinforced with Palm Fibers. Advances in Natural Fibre Composites. 1ed.: Springer International Publishing, 2018, v. p. 51-59.

LOPES, Alberto Costa. A Aventura da Cidade Industrial de Tony Garnier em Volta Redonda. Rio de Janeiro, 1993. 234 f. Dissertação de Mestrado em Geografia, apresentado ao Programa de Pós-Graduação em Geografia, Instituto de Geociências na Universidade Federal do Rio de Janeiro, 1993.

MELLO, Marisol Barenco. Espaçostempos da/na escola: o cotidiano e o transbordamento racional. IN GARCIA, Regina Leite. (org.). Método: pesquisa com o cotidiano. RJ: DP\&A, 2003. p. 262. 
MIGNOLO, Walter D. Histórias locais/Projetos globais: colonialidade, saberes subalternos e pensamento liminar. Belo Horizonte: Editora UFMG, 2003. p. 505.

Orientação Curricular da Secretaria Municipal de Volta Redonda. (2004). Departamento Pedagógico. RJ. p.215.

PAIS, José Machado. Vida cotidiana: enigmas e revelações. São Paulo: Cortez, 2003. p. 269.

Práticas Cotidianas e a Escola Pública em Volta Redonda - cidade-bairro - escola: subalternidade e gestão escolar. Niterói; Rio de Janeiro, 2007.309 f. Tese (Doutorado em Educação) - Programa de Mestrado e Doutorado em Educação, Universidade Federal Fluminense.

PARAISOALVES, Marcelo; MAGNAGO, Roberto Oliveira; MULINARI, Regina Daniela. Conflito sociambiental nas Áreas de Lazer em Volta Redonda: A Inclusão do Slackline no Cotidiano da cidade. Rio de Janeiro: Fundação Carlos Chagas Filho de Amparo à Pesquisa do Estado do Rio de Janeiro. 2018. E-26/010.002690/2014.

PERERIA, Dimitri Wuo et al. Esportes Radicais no Meio Ambiente Urbano no Município de São Paulo. Caderno de Educação Física e Esporte, v. 15, n. 1, p. 83-92.

PIMENTA, Solange Maria. A Estratégia da Gestão: Fabricando Aço e Construindo Homens. O Caso da Companhia Siderúrgica Nacional. Belo Horizonte, 1989. 733 f. Dissertação de mestrado em Administração apresentado a Faculdade de Ciências Econômicas da Universidade federal de Minas Gerais, 1989.

QUIJANO, Aníbal. Colonialidade do poder, eurocentrismo e América Latina. IN A colonialidade do saber e ciências sociais. Buenos Aires: Conselho Latinoamericano de Ciencias Sociales - CALACSO, 2005. p. 49.

QUINTANA, J. Alba, R.del Rey, I. Guillén-Guillamón. Comparative Life Cycle Assessment of gypsum plasterboard and a new kind of bio-based epoxy composite containing different natural fibers. Journal of Cleaner Production, 185(1), pp.408-420, 2018.

ZANINI, N. C.; PAIXAO, W. A.; DANTAS, I. R.; MULINARI, D. R. Influência do tratamento alcalino das fibras no comportamento térmico dos compósitos de PP reforçados com fibras da palmeira real australiana. In: $23^{\circ}$ Congresso Brasileiro de Engenharia e Ciência dos Materiais (23 CBECIMAT), 2018, Foz do Iguaçu. Influência do tratamento alcalino das fibras no comportamento térmico dos compósitos de PP reforçados com fibras da palmeira real australiana, 2018. 